\title{
Health-Related Quality of Life of Young Addict Women in Mashhad, IR Iran
}

\author{
Mohammad Khajedaluee ${ }^{1}$, Reza Assadi ${ }^{1}$, Maliheh Dadgar Moghadam ${ }^{1, *}$ \\ ${ }^{1}$ School of Medicine, Mashhad University of Medical Sciences, Mashhad, IR Iran \\ ${ }^{*}$ Corresponding author: Maliheh Dadgar Moghadam, School of Medicine, Mashhad University of Medical Sciences, Mashhad, IR Iran. Tel:+989155084676, Fax:+98-5118002385, E-mail: \\ maliheh_dadgar@yahoo.com.
}

Received: January 15, 2013; Revised: May 19, 2013; Accepted:Jun 02, 2013

\begin{abstract}
Background: Quality of life (QoL) stands for to the general well-being of the populations in the societies. Quality of life should not be confused with the concept of standard of living, which is based primarily on income. Instead, standard indicators of the QOL include not only wealth and employment, but also built environment, physical and mental health, education, recreation and leisure time and social belonging.

Objectives: This study attempted to evaluate the QoL of the young addicted women compared to non-addict controls.

Materials and Methods: This case-control study was conducted on young addict women aged between 16-25 years old using with BREF-WHOQOL questionnaire. The subgroups included vulnerable addicts, non-vulnerable addicts and healthy controls.

Results: The findings of the current study demonstrated that drug abuse led to reduce health-related QoL in all aspects of health compared with control group.

Conclusions: Health-related QoL was lower in all aspects of health compared with control group.
\end{abstract}

Keywords: Young adult; Substance-Related disorders; Quality of Life; Vulnerability

\section{Background}

In some societies, including our country, addiction is thought to be a masculine phenomenon. Nevertheless, according to the research results, women comprise approximately $10 \%$ of addicts in the country. Based on statistics, $50 \%$ female prisoners are in prisons in relation to drug abuse (1).

Although there is a significant gender difference in drug and alcohol abuse, but now a days alcohol and drug abuse is increasing in women. Compared to men, women are less likely to use illegal drugs, but when they start to being addicted, they tend to show addiction faster and would experience negative outcomes sooner than men (2).

Compared to other women, addict women suffer more from serious illnesses and non-communicable diseases, such as hepatitis and AIDS. Negative attitudes about addict women are a major obstacle in the course of treatment. However, women are less likely to receive support from families and friends to quit addiction. Treatment programs often lead to unexpected obstacles in women treatment procedure (3).

Drug abuse has a negative impact on the physical, psychological, social, economic and familial aspects of life. Results of research conducted by Karow to evaluate the role of the social and clinical variables in QoL of addicts, showed that personality disorders, interpersonal conflicts within a family and with spouse, and the need for physical and mental disorders treatment was significantly associated with lower QoL (4).

In a study conducted by Tracy and colleagues that have been performed with WHOQOLBREF questionnaire, findings revealed that the QoL of the addicts is less than normal subjects in various domains. The history of injuries/traumas significantly predicted the level of QoL in mental and physical domains (5).

The term Quality of life (QoL) is used to describe the general well-being of the populations. This term is

Implication for health policy/practice/research/medical education:

As addiction affect all aspects of health of women and increase risk of infectious, sexually transmitted and cardiovascular diseases, and induce mental disorders likewise depression and anxiety. Deterioration of socioeconomic conditions and social dysfunctions deepen mood disorders. These disorders lead to poverty, family breakdown and family rejection which particularly effects psychological and social communications of the sufferer. This study also confirmed that drug abuse might lead to the reduction of QoL of the abusers in all aspects of health, which we should pay a special attention to the consequences of prevention and health promotion activities.

Copyright @ 2013, Zahedan University of Medical Sciences; Published by Kowsar. This is an open-access article distributed under the terms of the Creative Commons Attribution License (http://creativecommons.org/licenses/by/3.0), which permits unrestricted use, distribution, and reproduction in any medium, provided the original work is properly cited. 
used in vast domains of international development, health and politics. Quality of life should not be confused with the concept of standard of living, which is based primarily on income. Instead, standard indicators of the QOL include not only wealth and employment, but also built environment, physical and mental health, education, recreation and leisure time, and social belonging (6).

\section{Objectives}

The current study attempted to evaluate the QOL of young addict women and comparing it with the nonaddict peers, based on aforementioned tool.

\section{Materials and Methods}

This case-control study conducted on young addict aged 16 to 25 in 2011-2012, Mashhad, Iran. The study groups including vulnerable addicts (those who were jailed to any reason), non-vulnerable addicts (without history of being in prison) and healthy women (those attended regional health centers for reasons other than addiction and had no history of addiction and jail). Sample size is calculated based on the mean difference between two groups (based on previous data studies) and ( $\alpha=0.05, \beta=0.2)$ which is equivalent to 80 person in each group.

Sampling method was randomized stratified in two age subgroups of 16-20 and 21-25 (to ensure including subjects below 20 years old) and in this age subgroups considered in all three groups of the study. All of the subjects signed an informed consent form for the participation in the study. All the information concerning their demographic, familial background, smoking, alcohol and pattern of smoking, and alcohol consumption habits were collected.

\subsection{Inclusion and Exclusion Criteria}

Vulnerable addict group included addicted women aged between 16 to 25 years in prison. No vulnerable addict group included addicted women aged between 16 to 25 years without history of being in prison. Control group included women aged between 16 to 25 years without a history of addiction and being in prison.

In this study the QoL of the individuals was evaluated by WHOQOL-BREF questionnaire. This questionnaire assesses the health related QoL in four domains:

-Physical Health Domain

-Psychological Domain

-Social relationship Domain

-Environmental Domain
This questionnaire contains 26 questions, the first two questions assess the QoL and health statuses in general, respectively, and the rest of questions ask about QoL particularly in the four mentioned domains. This tool is very popular and accepted worldwide. It has been translated to Persian and adjusted for this language in several studies, Yousefi et al. (7) and Nejat et al. (8). Data collection was conducted by trained inquirers participated in a training session to obtain the desired skill and be calibrated in their practice.

\section{2. Statistical Analysis}

After filling the questionnaires for all subjects, the obtained data was coded based on the answer key and for further statistical analysis all information entered to SPSS software version 11.5. The demographic characteristics of the subjects were presented in descriptive statistics. ANOVA test was used for the analysis of the quantitative variables between groups, when the normal distribution was confirmed; otherwise the Kruskall-Wallis test was implemented. In all of the statistical work the significant level was considered less than 0.05 .

\section{Results}

The demographic findings of these subjects are presented in Table 1. The evaluation of this data demonstrated that there is significant difference between groups in case of literacy level, occupation, personal and family income, place of living, smoking and alcohol consumption.

Physical health, mental health, interpersonal communication and environmental safety scores of the studied groups are shown in Diagram 1, 2, 3 and 4, given that the percent of physical health, mental health, interpersonal communication and environmental safety scores were higher in the controls comparing with the other two groups. The mentioned variables in two addict groups were not significantly different. ANOVA test showed a significant difference between three groups in case of physical health, mental health, interpersonal communication and environmental safety scores $(\mathrm{P}<0.001)$.

The mean score of total QoL is presented in Diagram 5. The mean score of total QOL in vulnerable addict, addict and healthy subjects was $(67.76 \pm 15.60),(74.100 \pm$ $11.21)$ and (95.05 \pm 10.69$)$ respectively. Hence the health status of the healthy group is significantly higher than both addict groups, and the addict group higher than the vulnerable ones $(\mathrm{P}<0.001)$. 
Khajedaluee M et al.

Table 1. Demographic Information of the Subjects

\begin{tabular}{|c|c|c|c|c|}
\hline & Vulnerable Addict, $\mathbf{N}=\mathbf{8 0}$ & Addict, $\mathbf{N}=\mathbf{8 0}$ & Control, $N=76$ & PValu \\
\hline Age & $21.1(3.33)^{\mathrm{a}}$ & $21.21(2.39)$ & $20.90(2.72)$ & 0.75 \\
\hline Literacy & & & & 0.001 \\
\hline Illiterate & $13(16.25)$ & $3(3.75)$ & 0 & \\
\hline Primary School & $26(32.5)$ & $18(22.5)$ & 0 & \\
\hline High School & $30(37.5)$ & $19(23.75)$ & $12(15.8)$ & \\
\hline High School Diploma & $9(11.25)$ & $36(45)$ & $30(39.5)$ & \\
\hline Associate Degree & $2(2.5)$ & $4(5)$ & $11(14.5)$ & \\
\hline Bachelor & 0 & 0 & $23(30.3)$ & \\
\hline Occupation & & & & 0.001 \\
\hline Housewife & $33(41.25)$ & $31(38.75)$ & $13(17.1)$ & \\
\hline Unemployed & $24(30)$ & $20(25)$ & $10(13.2)$ & \\
\hline Employed & $23(28.75)$ & $29(36.25)$ & $53(69.7)$ & \\
\hline Personal Income ${ }^{\mathrm{b}}$ & $209.11(163.73)$ & $67.69(82.85)$ & $147.04(189.90)$ & \\
\hline Family Income & $340.15(214.03)$ & $616.66(177.76)$ & $668.37(457.19)$ & \\
\hline Place of Living & & & & 0.001 \\
\hline Inside the City & $65(81.3)$ & $55(68.8)$ & $71(93.4)$ & \\
\hline City Suburb & $3(3.8)$ & $20(25)$ & 0 & \\
\hline County & $11(13.8)$ & $4(5)$ & $1(1.3)$ & \\
\hline Village & $1(1.3)$ & $1(1.3)$ & $4(5.3)$ & \\
\hline Religion & & & & 0.16 \\
\hline Shia & $77(96.3)$ & $76(95.3)$ & $76(100)$ & \\
\hline Sonni & $3(3.8)$ & $4(5)$ & 0 & \\
\hline Marital Status & & & & 0.001 \\
\hline Single & $19(23.8)$ & $38(47.5)$ & $75(98.68)$ & \\
\hline Married & $28(35)$ & $31(38.8)$ & 0 & \\
\hline Divorced & $31(38.8)$ & $9(11.3)$ & $1(1.31)$ & \\
\hline Widow & $2(2.5)$ & $2(2.5)$ & 0 & \\
\hline Smoking & $61(76.3)$ & $68(86.1)$ & $1(1.3)$ & 0.001 \\
\hline Alcohol & $34(42.5)$ & $13(16.9)$ & 0 & 0.001 \\
\hline
\end{tabular}

${ }^{a}$ Based on type of variable, mean and standard deviation or frequency

${ }^{\mathrm{b}}$ Income presented based on Tomans (Iran)

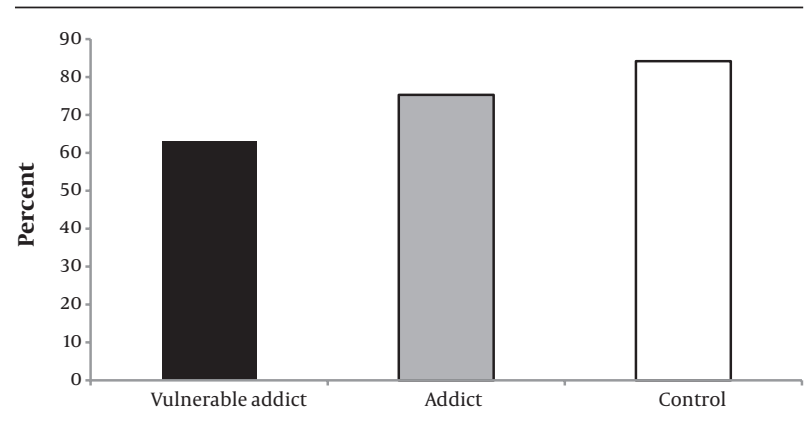

Diagram 1. Percent of Physical Health Score

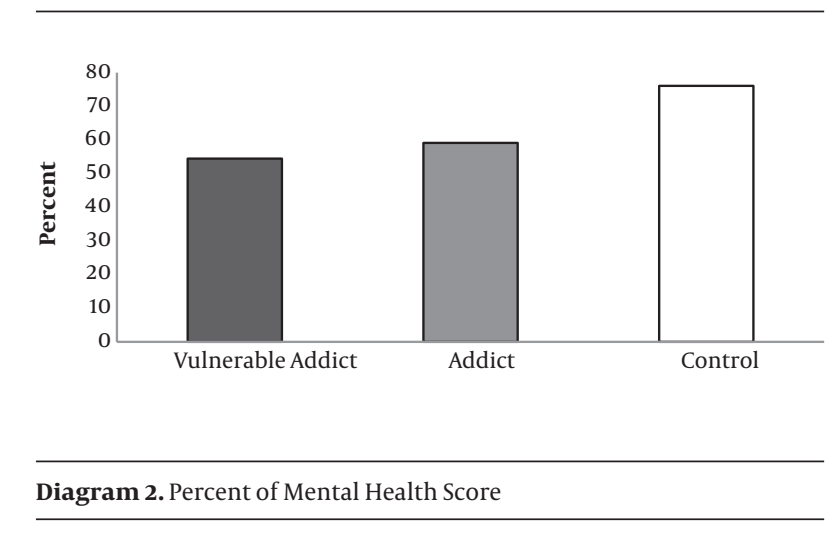




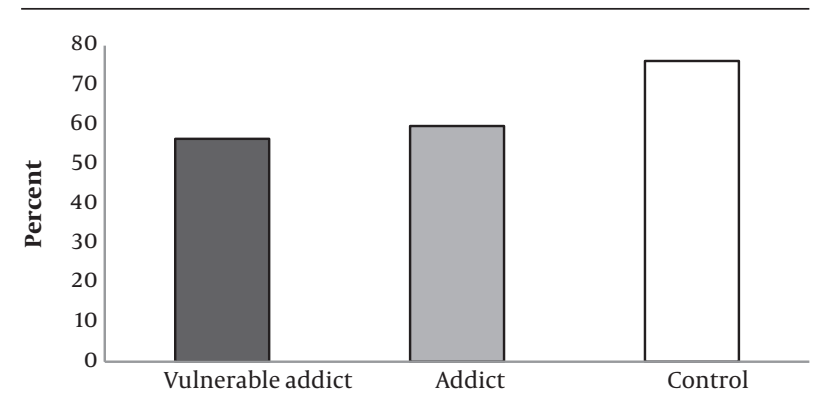

Diagram 3. Percent of Social Communication Score Safety

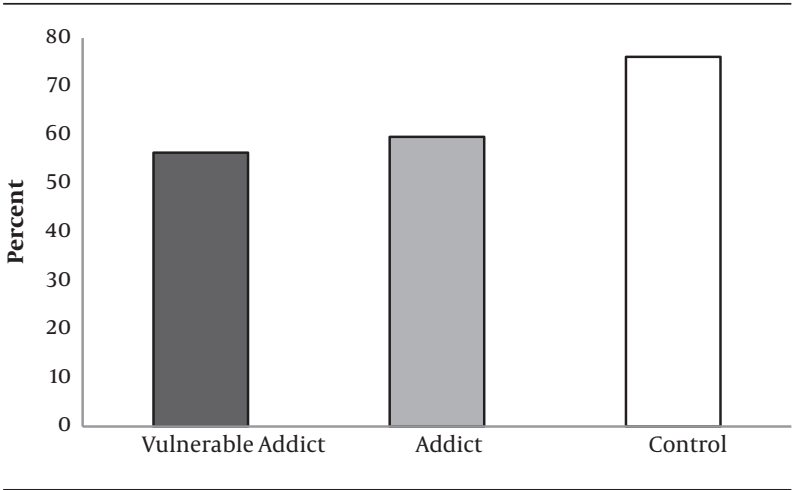

Diagram 4. Percent of Environment Health Score

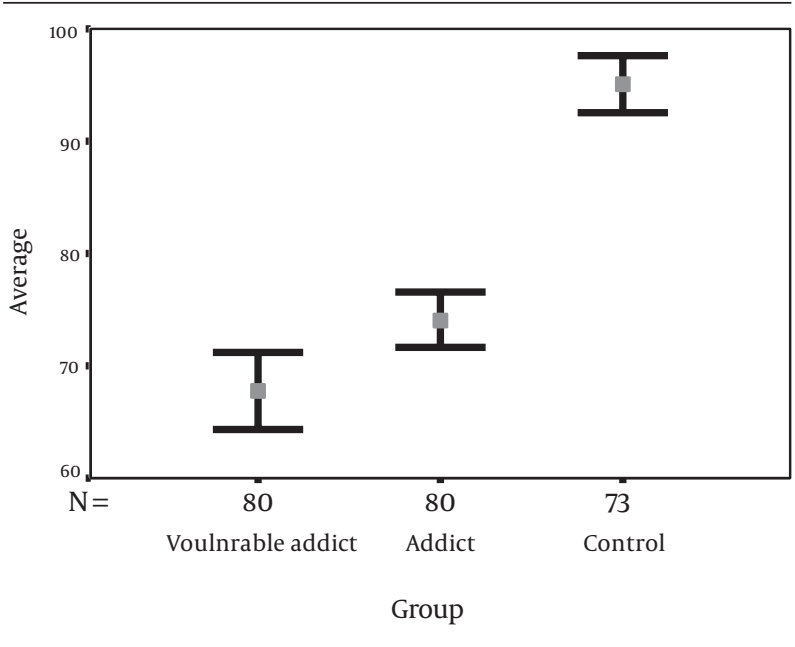

Diagram 5. Mean of Total QOL Score in Three Groups

\section{Discussion}

In the present study the overall score of QoL in general and in four sub-domains was significantly higher in controls compared with addict groups. Further studies showed low quality of life in addict person $(9,10)$.

In Samad Zadeh and colleagues study which was conducted to evaluate QoL of addict and healthy individuals in City of Tabriz, findings revealed that the addicts had an overall lower QoL compared with healthy individuals. They reported that healthy individuals had a better physical function, general health status, vitality, proper social function and mental health while less physical restriction, emotional conflict and physical pain were reported (11).

In another study conducted by Hojati et al. with the objective of evaluating the QoL of those referred to drug abuse treatment. The findings showed that fifty three percent of the addicts had "to some extent" desirable QoL and just eight percent reported high QoL (12).

Other studies have shown that drug abuse treatment has a positive impact on improving the quality of life for these individuals.

In Lua et al. study, the findings demonstrated that treatment has led to an improvement in the QoL and dramatic changes were observed in QoL of the individuals after treatment (13).

Vang and colleagues studied QoL of Heroin addicts who were under methadone maintenance therapy. Findings showed improvement of QoL in the course of treatment, and further therapy course was predicting for better QoL (14).

This study showed significant differences in factors such as education, employment, household income, personal income and parental educational as a social determinant of health between two addicts and control groups. Addiction affects all aspects of health of women, increases risk of infectious, sexually transmitted and cardiovascular diseases, and induces mental disorders such as depression and anxiety. Deterioration of socioeconomic condition and social dysfunction deepen the mood disorders. These disorders lead to poverty, family breakdown and family rejection that particularly influence psychological and social communication statuses and subsequently QoL of the sufferer.

The subjects of this study has been women aged between 16-25 years old, which is in active duration of life and the deterioration of QoL will affect their personal and social development as well as roles.

All of the questionnaires in this study were filled anonymously and the subjects were ensured that their confidentiality will be protected and will not be disclosed in any circumstance. All subjects signed and informed consent form for participation in this study.

\section{Acknowledgments}

We are grateful from the province health center, prison organization and welfare organization. We also acknowledge the chancellor for research of Mashhad University of Medical Sciences for funding and supporting this study. This paper is part of dissertation of the third author.

\section{Authors' Contribution}

The first author designed the evaluation and performed 
statistical analysis. Second author revised the manuscript and third author collected clinical data and participated in analysis and interpreting data and drafted the manuscript. All authors read and approved the final manuscript.

\section{Financial Disclosure}

There is no conflict of interest.

\section{Funding/Support}

There is not any Funding or support.

\section{References}

1. Poorasgar N. Available from: htpp://www.nimapoorasgar.blogfa.com.

2. Safari F. [Addiction and Women, Gender differences in substance abuse treatment]. 1st ed. Tehran: Iranian nationalcenter for addiction study; 2004.

3. Addiction EMCfDaD. Differences in Patterns of drug use between women and men. [updated 2005; cited];2005 Available from: http://www.emcdda.europa.eu/html.cfm/index34278EN.html.

4. Karow A, Verthein U, Krausz M, Schafer I. Association of personality disorders, family conflicts and treatment with quality of life in opiate addiction. Eur Addict Res. 2008;14(1):38-46.

5. Tracy EM, Laudet AB, Min MO, Kim H, Brown S, Jun MK, et al. Prospective patterns and correlates of quality of life among women in substance abuse treatment. Drug Alcohol Depend. 2012;124(3):242-9.

6. Wikipedia [updated 2012; cited 2012];2012 Available from: http:/ en.wikipedia.org/wiki/Main_Page.

7. Usefy AR, Ghassemi GR, Sarrafzadegan N, Mallik S, Baghaei AM, Rabiei K. Psychometric properties of the WHOQOL-BREF in an Iranian adult sample. Com Ment Health J. 2010;46(2):139-47.

8. Nejat S, Montazeri A, Mohammad K, Majdzadeh SR. [The World Health Organization quality of Life (WHOQOL-BREF) questionnaire: Translation and validation study of the Iranian version]. J Sch Public Health Res. 2007;4(4):1-12.

9. Esfandabad H, Naderi S. A comparative study of the quality of life and religious attitude among Addicted / non-addicted individuals in Kerman city. J Psychlo Stud. 2009;5(1):139-52.

10. Maremmani I, Stefania C, Pacini M, Maremmani AG, Carlini M, Golia F, et al. Differential substance abuse patterns distribute according to gender in heroin addicts. $J$ Psychoactive Drugs. 2010;42(1):89-95

11. Samadzadeh N, Sharifi H, editors. Comparison of health related QOL of healty and addicts $]$ in persian. The first international student congress of addiction; 2012; Urmia.

12. Hojjati H, Alostani S, Akhondzadeh G, Heydari B, Sharifnia H. Psychiatric health and quality of life in drug addiction people. $J$ Shaheed Sadoughi Un Med Sci. 2010;18(3):207-14.

13. Lua PL, Talib NS. A 12-month evaluation of health-related quality of life outcomes of methadone maintenance program in a rural Malaysian sample. Subst Use Misuse. 2012;47(10):1100-5.

14. Wang PW, Wu HC, Yen CN, Yeh YC, Chung KS, Chang HC, et al. Change in quality of life and its predictors in heroin users receiving methadone maintenance treatment in Taiwan: an 18-month follow-up study. Am J Drug Alcohol Abuse. 2012;38(3):213-19. 